\title{
Comunicação como ferramenta para divulgar e promover a Declaração Universal sobre Bioética e Direitos Humanos
}

\author{
Rodrigo Caetano ${ }^{1}$, Volnei Garrafa ${ }^{2}$
}

\begin{abstract}
Resumo
A Declaração Universal sobre Bioética e Direitos Humanos (DUBDH) é um dos pilares que pautam a agenda biotecnocientífica mundial do século XXI. O documento é insuficientemente conhecido em âmbito nacional e internacional, tanto pela população como pela comunidade acadêmica. Para que seu conteúdo seja assimilado é indispensável a adoção de estratégias de comunicação com vistas a divulgar os temas abordados. O trabalho objetiva propor, por meio de um plano de comunicação, uma melhor divulgação internacional dos princípios da DUBDH e sua inclusão nas políticas públicas, no cotidiano das universidades, centros de pesquisa e pelos próprios cidadãos. Por meio de estratégias programáticas o estudo propõe instrumentos democráticos cujas metas são o empoderamento, a libertação e a emancipação - referenciais da bioética de intervenção, linha conceitual de fundamentação latino-americana e epistemologicamente consolidada - das populações mais vulneráveis. A consequência desejada é maior divulgação internacional da bioética, que poderá contribuir para transformar a realidade social.
\end{abstract}

Palavras-chave: Bioética. Direitos humanos. Comunicação. Políticas públicas.

\section{Resumen}

\section{Comunicación como herramienta para divulgar y promover La Declaración Universal sobre Bioética y Derechos Humanos}

La Declaración Universal sobre Bioética y Derechos Humanos (DUBDH) es una de las bases de la agenda biotecnocientífica mundial del siglo XXI. Dicho documento es insuficientemente conocido en nivel nacional e internacional, tanto por la población como por la comunidad académica. Para mejor asimilación de sus principios y contenido, es indispensable la adopción de estrategias de comunicación para divulgar los temas abordados. El trabajo objetiva, por medio de un plan de comunicación, proponer una mejor divulgación internacional de los principios de la Declaración y su inclusión en las políticas públicas, en el cotidiano de las universidades, centros de pesquisas e por los propios ciudadanos. Por medio de estrategias programáticas, el estudio sugiere herramientas democráticas cuyas metas son el empoderamiento, la liberación e la emancipación - que son referencia de la Bioética de la Intervención, línea conceptual de fundamentación latinoamericana y epistemologicamente consolidada - de las poblaciones más vulnerables. La consecuencia deseada es la mayor divulgación internacional de la bioética que podrá contribuir para la transformación de la realidad social.

Palabras-clave: Bioética. Derechos humanos. Comunicación. Políticas públicas.

\begin{abstract}
Communication as a tool to promote and spread the Universal Declaration on Bioethics and Human Rights

The Universal Declaration on Bioethics and Human Rights is one of the basis of the XXI century world biotecnocientific agenda. The referred document is insufficiently national and internationally known, not only by the population but also by the academic community. In order to allow the Declaration principles and contents to be more assimilated, it is necessary to adopt communication strategies to promote bioethics themes. This paper aims to propose - throughout a communication plan - an international promotion of the Declaration principles in public policies and its inclusion in universities, research centers and by citizens themselves. Besides, this study aims to establish democratic devices whose purposes are the empowerment, the liberation and the emancipation - principles of the Bioethics of Intervention, a conceptual line with foundations in Latin America and epistemologically consolidated - of the most vulnerable populations. The desired consequence is a bigger international spread of bioethics which will contribute to transform social reality.

Key words: Bioethics. Human rights. Communication. Public policies.
\end{abstract}

1. Doutorando rodcaetano@hotmail.com 2. Pós-doutor garrafavolnei@gmail.com - Universidade de Brasília, Brasília/DF, Brasil.

Rodrigo Caetano - SQSW 301 Bloco B apt 311 CEP 70673-102. Brasília/DF, Brasil.

Declaram não haver conflito de interesse. 
A Declaração Universal sobre Bioética e Direitos Humanos (DUBDH), adotada durante a $33^{\text {a }}$ Conferência Geral das Nações Unidas para a Educação, a Ciência e a Cultura (Unesco), em outubro de 2005, em Paris, representa um marco para a bioética mundial.

Com esse documento internacional, os temas bioéticos que contextualizam o ser humano como agente moral, social, cultural e político estão incluídos na nova agenda de debates do século XXI. Sané ressalta que a DUBDH é o primeiro marco histórico, amplo e internacional, dos princípios da bioética ${ }^{1}$. Para Saada, representa mudança paradigmática no conceito de bioética: $A$ DUBDH abre novos espaços para que a reflexão ética seja ferramenta necessária para que governos possam estabelecer leis, normas e legislações adequadas no campo bioético ${ }^{2}$.

No mesmo sentido, Barbosa ressalta que o conteúdo deste documento consolida um avanço concreto para um novo referencial epistemológico e uma nova agenda temática para a bioética do século XXI: uma bioética mais humana, mais palpável e mais próxima dos verdadeiros conflitos persistentes que assolam a maioria dos países periféricos da Terra ${ }^{3}$.

O documento, considerado juridicamente norma não vinculante, sem força de lei, mas com significado político importante, foi firmado por 191 países signatários e abordou questões sociais (dignidade humana, violência, combate à pobreza, solidariedade), sanitárias (acesso universal a sistemas de saúde, equidade na atenção) e ambientais (qualidade da água, biodiversidade). A DUBDH oferece ainda orientação para decisões ou práticas de indivíduos, grupos, comunidades, instituições e empresas públicas e privadas ${ }^{4}$.

A DUBDH representa grande avanço político e teórico para um mundo socialmente mais justo. Durante sua construção, entretanto, aconteceram diversos conflitos entre as nações mais ricas e pobres; entre o mundo centrado no contexto euroestadunidense e o mundo periférico. Nas reuniões preparatórias, países mais ricos defenderam um texto exclusivamente focado em questões biomédicas e biotecnológicas. Por sua vez, os países pobres e em desenvolvimento batalharam por avançar também em questões sociais, ambientais e sanitárias.

O compromisso com a comunicação e divulgação das premissas do texto oficial está previsto no artigo 22 da DUBDH: os Estados devem tomar todas as medidas adequadas de caráter legislativo, administrativo ou de qualquer outra natureza, de modo a implementar os princípios estabelecidos na presente Declaração e em conformidade com o direito inter- nacional e com os direitos humanos. Tais medidas devem ser apoiadas por ações nas esferas da educação, formação e informação ao público ${ }^{3}$. Desde 2005, passos foram dados para tornar público esse conteúdo, mas ainda falta avançar para que a difusão se torne realidade prática e aplicada na vida de pessoas, comunidades e países.

A falta de conhecimento e entendimento da DUBDH é fator que contribui para a manutenção do status quo desigual; contribuindo para que populações permaneçam distantes de usufruir de diversas nuances da justiça social. Isso ocorre porque esse desconhecimento, aliado a fatores como baixa escolaridade e falta de debate de temas cruciais para a vida das pessoas, reforça a ignorância, apatia e ausência de mobilização para pressionar poderes públicos e privados a adotarem soluções que objetivem o desenvolvimento social e econômico para todos.

Segundo Lorenzo ${ }^{5}$, a vulnerabilidade social é um fenômeno determinado pela estrutura de vida cotidiana das pessoas e comunidades, diretamente relacionado aos fatores que a determinam, tais quais falta de recursos como renda, informação, conhecimento e tecnologias e falta de acesso a poderes públicos e outros tipos de representação social ${ }^{6}$. Assim, como resultado desse processo de alienação as populações vulneráveis são alijadas nas decisões políticas, deixando de participar de maneira integrada nas decisões que afetam a sociedade em geral.

A ausência da divulgação das premissas da DUBDH, tanto nacional quanto internacionalmente, apresenta reflexos diretos em diferentes setores e áreas de atividade. No Brasil, por exemplo, em uma votação apertadíssima no Supremo Tribunal Federal (STF), em 2008, com seis votos a favor e cinco contra a liberação do uso de células-tronco para pesquisas e terapias, os ministros da máxima Corte jurídica do país em nenhum momento se basearam e citaram as premissas da Declaração Universal sobre Bioética e Direitos Humanos.

Essa ausência torna-se ainda mais flagrante (e preocupante) quando se percebe que a DUBDH é considerada o documento internacional mais atual e balizador nesse sentido, que prega valores e estabelece premissas em defesa da vida e dos direitos humanos. Esse desconhecimento pode decorrer da desinformação de magistrados que ocupam posição de notório saber e, na hora de consolidar seus argumentos, ignoraram a importância dos conceitos contidos no documento.

O fato não pode ser tomado de maneira isolada, o que demonstra e reforça a necessidade de investir 
em políticas de comunicação com relação à DUBDH nas áreas pública e privada. Por isso, o presente estudo propõe o uso de ferramentas e estratégias do campo da Comunicação para contribuir na divulgação, promoção e popularização do conteúdo, dos conceitos e das bases éticas contidas no documento.

Os artigos 22 e 23 da Declaração defendem que informações e conceitos do texto sejam difundidos e divulgados principalmente entre os jovens - responsáveis por construir o futuro. Ambos os artigos reforçam a necessidade de se ter um instrumento atual, dinâmico e hábil que possa provocar reflexões e transformações práticas - no caso, um plano de comunicação estruturado, objeto de discussão deste trabalho.

\section{Bioética de intervenção: politizando a divulgação da DUBDH}

Para que qualquer instrumento de divulgação traga resultados práticos que motivem o processo de transformação social, é fundamental que exista o compromisso ético e político nesse sentido. Assim, as nações participantes da construção da DUBDH estão comprometidas com sua disseminação e difusão dos seus conceitos.

Esse formato político de compromisso mundial vem alcançado resultados estratégicos positivos, como o acordo para os Objetivos de Desenvolvimento do Milênio proposto pelas Nações Unidas em $2000^{7}$. Nele, a comunidade internacional de nações fixou uma série de compromissos para serem cumpridos pelos estados-membro em 15 anos. Ao todo, são oito temas centrais, dentre os quais a saúde pública e o meio ambiente, divididos em 18 objetivos e 48 indicadores. Cada país, de acordo com sua realidade, comprometeu-se a alcançar determinados índices populacionais ligados à inclusão social para, juntos, alterarem o destino da humanidade.

As Metas do Milênio, nome popularmente conhecido, ganharam espaço na agenda política internacional, sendo debatidas por entidades governamentais, empresariais e sociedade civil. Por terem sido difundidas globalmente com metas claras e objetivas quanto a resultados, cada Estado e sua sociedade foram instigados a criar suas próprias estratégias para cumprir as metas assumidas.

Neste contexto, a comunicação, para Melo ${ }^{8}$, funciona como ponte para a realização prática daquela agenda política, haja vista ser a base das relações entre os indivíduos e grupos na sociedade. Os meios de comunicação podem contribuir para mudanças da dinâmica nas relações interpessoais, tendo a capacidade de intervir no tecido social, respeitando e - em alguns casos específicos e de modo positivo - ultrapassando barreiras culturais.

Mas a comunicação de uma diretriz (como propõe a DUBDH) necessita de estratégia de divulgação para que a mensagem atinja os objetivos desejados. Neste estudo, a comunicação se associa à bioética de intervenção, que defende a politização dos temas morais como forma de aplicação da chamada ética aplicada, em substituição à bioética meramente normativa ou descritiva ${ }^{9}$. Para ela, países periféricos necessitam de novo enfoque bioético, baseado em práticas intervencionistas, diretas $e$ duras, que instrumentalizem a busca de uma diminuição de inequidades ${ }^{10}$, ou seja, aponta o caminho de intervenção do Estado para superar as desigualdades e possibilitar a inclusão social para os mais vulneráveis ${ }^{9}$.

Ao defender a politização dos temas da bioética em geral, esta linha epistemológica de trabalho utiliza a perspectiva do filósofo francês, de origem grega, Cornelius Castoriades, para quem a política é $o$ campo onde verdadeiramente se dão as grandes decisões, que alijam ou incluem indivíduos como beneficiários do desenvolvimento científico e tecnológico ${ }^{11}$.

Sendo a política caminho necessário para que o indivíduo atue e influencie decisões importantes, é fundamental que os atores na luta a favor da inclusão social se empoderem por meio de mais conhecimentos e direitos, e se libertem no mais amplo sentido que o conceito de Paulo Freire para libertação permita, emancipando-se ${ }^{12}$. A comunicação e a atuação direcionada estratégica podem ajudar em cada um desses processos.

O empoderamento dos grupos vulneráveis fortalece e corrobora a libertação, defendida por Freire, para quem os sujeitos sociais são atores políticos cuja ação pode manter ou alterar o status quo ${ }^{13}$ : Comunicação [é] a co-participação dos Sujeitos no ato de pensar (...) [ela] implica uma reciprocidade que não pode ser rompida (...) comunicação é o diálogo na medida em que não é transferência de saber, mas um encontro de Sujeitos interlocutores que buscam a significação dos significados.

A liberdade é mais do que o reconhecimento da existência de poder. $\mathrm{O}$ grupo que possui autonomia e liberdade marca posição, estabelece um locus e demonstra uma carga de atuação e de poder no contexto democrático contra a dominação socioeconômica e cultural. A bioética de intervenção defende que a luta política deve resultar em liberdade, 
a partir da tomada de consciência sobre as forças que os oprimem e pela ação concreta de oposição a elas ${ }^{9}$.

Por último, como consequência natural dos dois pilares descritos, a emancipação entra como importante marco teórico para a bioética de intervenção, significando que: Só é emancipado aquele que suprimiu sua dependência, que alcançou o domínio sobre si mesmo e pode garantir não apenas a sobrevivência, mas suas escolhas frente aos meios de alcançar essa sobrevivência ${ }^{12}$. Essa linha de pensamento defende que $o$ ato de se emancipar tem caráter político. Emancipar-se deve ser um direito conquistado, e não concedido.

Por isso, a divulgação dos conceitos principais da DUBDH tem de ser encarada como ato político global, intervencionista, que deve ser assumida de maneira direta, com estipulação de metas anuais, pelas 191 nações que assinaram o documento. E esse ato intervencionista depende, entre outros pontos, de um plano de ação comunicativa para alcançar o objetivo de transformar a realidade social.

\section{O poder da comunicação e suas ferramentas}

O conceito de comunicação se ampliou no mundo globalizado. Atualmente, são necessários não só elementos básicos, como emissor, receptor e mensagem, mas também aspectos como a compreensão do conteúdo, a assimilação e processamento de informações para provocar a ação consciente e, possivelmente, transformadora na vida de cada um e de todos.

A comunicação influencia comportamentos individuais e coletivos e pode auxiliar na ampliação do debate para posterior conscientização sobre os mais diversos assuntos e para o posicionamento da pessoa como cidadão. É com este objetivo que um plano de comunicação será desenhado no contexto do presente trabalho, como ferramenta prática para auxiliar em um processo mais amplo de tentativa de divulgação da DUBDH na comunidade de nações, possibilitando resultados práticos para a vida cotidiana das pessoas.

Segundo Castells ${ }^{14}$, há atualmente uma nova forma de relação entre economia, Estado e sociedade, como resultado da revolução tecnológica que está na base da chamada sociedade da informação. Nela, a comunicação assume grande relevância, atuando na elaboração de conceitos, percepção de consciência e entendimento das questões mundiais relevantes para a humanidade. $\mathrm{O}$ desafio está em sensibilizar as pessoas e, no caso do conteúdo da DUBDH, fazer com que temas importantes estejam tangíveis, inseridos, percebidos e assimilados no dia a dia de todos. Como fazer isso? Entre outras ações, por meio da aplicação de estratégias adequadas de comunicação ${ }^{15}$ - como visto mais adiante.

Aplicada como ferramenta, a comunicação pode oferecer resultados práticos de assimilação das propostas presentes no documento do organismo internacional, como o respeito à dignidade humana, à igualdade dos direitos e à justiça. Estudos na área de percepção pública apontam que a divulgação científica de temas como desenvolvimento sustentável, aquecimento global, biotecnologia e transgênicos, por exemplo, aliada a outras estratégias nos mais diversos meios de comunicação de massa, garantem resultados significativos para o aumento do entendimento neles contidos ${ }^{16}$.

No caso da DUBDH, há uma gama de assuntos que vão desde o respeito à dignidade humana, passando por compreensão de termos de consentimento em pesquisa científica, até o acesso aos sistemas de saúde e a medicamentos. Devido a essa diversidade, a compreensão pode ser mais complexa. Com a intenção de trazer temas para o cotidiano das pessoas, é fundamental usar da comunicação de massa para dar visibilidade às informações, sem, evidentemente, perder qualidade.

De acordo com Castells, o pensamento coletivo (que não é a soma dos pensamentos individuais em interação, mas sim um pensamento que absorve tudo e é difundido por toda a sociedade) se elabora na comunicação. É da comunicação que vêm as imagens, as informações, as opiniões e é por meio desses mecanismos de comunicação que a experiência é divulgada e transmitida ao coletivo/na coletividade ${ }^{17}$.

Assim, a comunicação entra como o meio pelo qual a DUBDH pode se tornar amplamente divulgada, conhecida e popularizada para que seja levada da teoria à prática, influenciando a responsabilidade social dos governos e da sociedade civil em assuntos como saúde e bem-estar coletivo, preservação do meio ambiente e da diversidade cultural e as lutas contra a pobreza e exclusão social ${ }^{18}$.

Habermas propõe um modelo teórico - a Teoria da Ação Comunicativa - no qual as pessoas interagem e, pela utilização da linguagem, se organizam socialmente, buscando o consenso de forma livre de qualquer coação externa e interna. Esse autor acredita que, para haver transformação na sociedade e para a resolução de graves problemas sociais, é necessário o resgate da racionalidade comunica- 
tiva, na qual o diálogo e o agir comunicativo sejam o motor da interação social e da construção de espaços de poder com a ação de indivíduos críticos e participativos ${ }^{19}$.

A linguagem é peça fundamental da Teoria da Ação Comunicativa. Para Habermas os indivíduos socializados, quando no seu dia a dia se comunicam entre si por meio da linguagem comum, não têm como evitar que se empregue essa linguagem também no sentido voltado ao entendimento. $E$, ao fazer isso, eles precisam tomar como ponto de partida determinadas pressuposições pragmáticas, nas quais se faz valer algo parecido com uma razão comunicativa ${ }^{20}$.

Por isso, o presente plano de comunicação propõe o uso de técnicas atuais, das mais diferentesáreas, e estratégias para que a população aumente a assimilação de temas e consiga trazê-los para o entendimento da realidade no seu contexto de vida. Esse processo torna o ser humano cada vez mais preparado para exercer a cidadania, dando-Ihe mais autonomia, dignidade e justiça e, por conseguinte, mais consciência para lutar pelos seus direitos e respeitar seus semelhantes, uma das premissas da bioética ${ }^{1}$.

Miguel destaca a importância da comunicação e sua relação com a política: $A$ mídia é, nas sociedades contemporâneas, o principal instrumento de difusão das visões de mundo e dos projetos políticos; dito de outra forma, é o local em que estão expostas as diversas representações do mundo social, associadas aos diversos grupos e interesses presentes na sociedade ${ }^{21}$

\section{O plano de comunicação para divulgação, pro- moção e popularização da Declaração}

Todo plano de comunicação possui um roteiro básico que pode ser adequado de acordo com a realidade de cada órgão, país, governo ou empresa que resolva adotá-lo. O plano aqui proposto pode representar um esforço de planejamento estratégico, produzido, principalmente, para aumentar a visibilidade de um assunto, de um produto ou da empresa para o público em geral ou para públicos específicos ${ }^{22}$.

Um plano de comunicação não se resume apenas à divulgação; suas propostas são formadas para fortalecer alguma marca, no presente caso, a Declaração Universal sobre Bioética e Direitos Humanos da Unesco como proposta para a agenda social internacional no século XXI. O plano em questão visa a criação de uma visibilidade maior para os conceitos bioéticos que possam mobilizar politicamente e transformar, na prática, a realidade das pessoas. Seu objetivo central é, além de contribuir para maior visibilidade da bioética no contexto mundial, ajudar na melhoria da qualidade de vida dos vulneráveis e estabelecer relações socialmente mais justas para a humanidade.

Usualmente, um plano de comunicação segue várias etapas, tais como: análise da situação, orientação estratégica, escolha dos meios, orientação criativa, preparação de orçamento, realização técnica e avaliação de resultados. Vale ressaltar que o plano aqui sugerido consistiria no reforço de um conjunto de medidas e ações socioeconômicas, políticas e de comunicação que precisam andar concomitantemente em cada país.

A proposta não se esgota em si e deve ser encarada como ponto de partida, necessitando eventualmente ser revista, atualizada (devido à velocidade dos avanços tecnológicos) e modificada. A sugestão com a apresentação do presente plano de comunicação não seria construir um manual estático e absoluto das ações de comunicação. Muito menos, teria a pretensão de esgotar todas as possibilidades para que a DUBDH seja conhecida, divulgada e popularizada. A educação permanente em bioética é peça fundamental para a tomada de consciência própria e da sociedade, além de ajudar, de maneira prática, a mudar a situação dos menos favorecidos social e economicamente.

Aumentar o acesso à informação é desafio mundial e, ao mesmo tempo, obstáculo para alcançar o objetivo de divulgar os valores da DUBDH. A mesma barreira pode ser enfrentada para a assimilação desses conteúdos não só pelas pessoas sem escolaridade, mas também por quem faz as leis no país, por atores envolvidos nas políticas nacionais e locais e por cidadãos comuns, das mais diversas classes sociais. Os dois aspectos citados devem ser considerados para a elaboração do plano de comunicação do tipo aqui proposto.

\section{Definição da mensagem}

Uma comunicação depende de muitos aspectos para que seja efetiva. Entre eles, a definição da mensagem e dos meios adequados para sua propagação ${ }^{23}$. Uma mensagem pode ser transmitida em conversas pessoais, durante seminários profissionais, por e-mails ou telefones celulares, por atuação da publicidade ou pela mídia e seus veículos (televisão, rádio, jornal, revista, internet). Na era da sociedade da informação, uma mensagem pode circular 
com rapidez assustadora e causar efeitos tanto positivos quanto negativos. Por isso, as mensagens do plano precisariam ser definidas e bem elaboradas, em linguagem acessível aos mais diversos públicos. Seriam necessários produtos, ações, meios de comunicação, interlocutores e porta-vozes que criem e reproduzam mensagens e informações de maneira sistêmica para a sociedade.

Para que essa comunicação aconteça de fato, as mensagens precisariam ser/ter: 1) objetivas, curtas, simples e de fácil compreensão; 2) linguagem apropriada ao nível de compreensão dos receptores, à faixa etária, ao gênero, à etnia, entre outros aspectos; 3 ) contextualizadas, para que o receptor se sinta realmente participando da comunicação e acredite que faz parte deste processo inclusivo; 4) apelo visual, sensorial e emocional para que facilite a abertura, a confiança, a honestidade e a cooperação do emissor com o receptor; 5) ser adaptadas à realidade do receptor - o que envolve aspectos socioeconômicos do público, além da capacidade física de receber determinada mensagem. (Por exemplo, como tornar real uma mensagem a um surdomudo? E a uma pessoa cega?); 6) alto grau de transmissão com baixo custo; 7) efeito persuasivo, serem criativas, ousadas e inovadoras.

\section{Análise de situação, pesquisas e orientação estratégica}

O ponto de partida para um plano de comunicação seria o diagnóstico e a análise da situaçã̃o e dos cenários. Muito provavelmente, a maioria da população mundial não conhece a DUBDH e o seu conteúdo. Contudo, seus conceitos podem estar no cotidiano moral das pessoas sem que elas mesmas saibam.

Para traçar um diagnóstico e identificar quais são as maiores demandas, seria necessária a realização de pesquisas de opinião pública para mapear a percepção e identificar o grau de informação e o comportamento de determinados setores da sociedade em relação a temas da DUBDH. O estudo com questões quanti e qualitativas é o ponto de partida para que cada país identifique suas necessidades e trace um diagnóstico. Ele também servirá de base para orientar as estratégias deste plano de comunicação. As soluções precisam ser customizadas a partir desse levantamento inicial.

Um projeto desse tipo pode ser implementado nacional, regional ou mesmo internacionalmente, dependendo da ambição e/ou objetivos dos seus executores. $O$ propósito do presente estudo não é a execução da proposta em si, mas sim proporcionar elementos teóricos e metodológicos, além de ferramentas práticas, para a execução de projetos de divulgação da DUBDH em diferentes situações no âmbito interno dos países ou em esforços conjuntos entre eles.

A realização de pesquisas periódicas seria importante instrumento para saber como as pessoas percebem, entendem e assimilam determinados temas e situações. $O$ resultado desse conjunto de opiniões confere ao planejamento de comunicação maior probabilidade de êxito. Desde já, o plano sugeriria também que, em cada local onde fosse executado, se fizessem estudos para identificar os principais porta-vozes (líderes de opinião) na sociedade civil e no campo político (parlamentares, governadores, prefeitos) e seus discursos sobre os principais temas da DUBDH. O resultado da pesquisa serviria para orientar uma política de relacionamento e de abastecimento de informações a serem retransmitidas à sociedade em geral.

Outro foco importante seria a mídia. O plano sugeriria que fosse efetuado um levantamento de quais são os temas mais presentes relacionados à bioética, tratados nos principais meios de comunicação dos lugares escolhidos para sua execução. Neste retrato, seria importante identificar qual a frequência de reportagens, notícias, artigos e comentários que citem direta ou indiretamente questões bioéticas. Um estudo importante, ainda relacionado à mídia, seria destinado a saber quais são os veículos e os jornalistas que mais escrevem sobre os temas bioéticos e que tipo de opinião costumam emitir.

A partir dessas análises seria possível pensar em estratégias de comunicação e de relacionamento para fornecer informações a diversos públicos, ampliar o número de profissionais que possam se manifestar com propriedade sobre os temas, aumentar a frequência de publicação e debate de temas bioéticos na mídia, no meio político e na sociedade e, por último, qualificar o discurso de quem realiza a cobertura jornalística. Desta forma se estaria dando visibilidade à temática e embasando a ampla discussão acerca de tais temas.

\section{Definição de públicos-alvo}

O desafio de divulgar e promover a DUBDH entre os mais diversos públicos que compõem a população de um país é bem complexo, já que cada nação possui um sistema social, econômico, políti$\mathrm{co}$, religioso e cultural distinto. Mas, dentro desse 
universo amplo, há setores específicos que precisariam ser sensibilizados e informados para que mais uma vez, aplicando premissas da bioética de intervenção - a troca de ideias e debates ocorra e possa influenciar a criação ou discussão de políticas públicas, beneficiando o maior número de pessoas no âmbito da população.

O papel do Estado - como ente representativo nas Nações Unidas - é estratégico. Precisa liderar e conduzir o processo de conscientização e discussão dentro da esfera pública e envolver toda a sua estrutura de poder: quem administra o Estado, quem constrói as leis do país, quem delibera sobre a aplicação e o cumprimento das leis e quem sofre as consequências diretas delas. A esfera governamental, nos países democráticos, é alvo de influência e pressão de vários setores da sociedade civil. Uma democracia mais madura permite que a população perceba seu poder e atue nas decisões do Estado.

Para que a DUBDH e seus conceitos tenham maior legitimidade do que aquela conferida pelos poderes públicos, torna-se também fundamental o envolvimento da sociedade civil organizada no processo de divulgação, promoção e implantação, responsável por exercer o controle social. Miguel ressalta que (...) a desigualdade de acesso à discussão pública não é efeito apenas do controle da mídia, mas também da deslegitimação da expressão dos dominados no campo político, que exige o manejo de determinados modos de discurso ${ }^{24}$.

Diferentes representações de trabalhadores, setor empresarial, organizações não governamentais, formadores de opinião, mundo acadêmico, profissionais das áreas que se relacionam diferentemente às decisões bioéticas, bem como demais profissionais das áreas da saúde, educação, comunicação, cultura, ciência e tecnologia, pesquisa, meio ambiente e direitos humanos ${ }^{4}$, precisam ser envolvidos neste processo de conhecimento, entendimento, divulgação, intervenção e, por fim, transformação social do Estado.

O plano de comunicação prevê um trabalho mais próximo a públicos prioritários. É a primeira fase, momento em que os conceitos, debates, discussões e ações práticas se multiplicariam e, aos poucos, serviriam de agente transformador da realidade. Nesse primeiro instante, os públicos prioritários seriam: a) imprensa, profissionais de comunicação e formadores de opinião; b) empresários e profissionais do setor empresarial; c) sociedade civil organizada; d) gestores públicos, políticos e parlamentares; e) entidades ligadas ao tema da Declaração.
Para cada público seriam propostas estratégias e abordagens específicas. Porém, os principais eixos de atuação seriam:

- capacitar profissionais das mais diferentes formas para qualificar o discurso, a atuação e a intervenção em seu nicho de atuação;

- realizar ações de relacionamento com influenciadores e líderes de cada um dos públicos-alvo;

- criar redes públicas de conhecimento e de troca de informação;

- estimular interação para que os participantes possam vivenciar determinadas situações in loco, experimentando e relatando situações;

- desenvolver espaços públicos e midiáticos para fomentar debates e discussões sobre temas bioéticos;

- criar ações permanentes para manter os assuntos na agenda política e social do país;

- promover políticas que valorizem, financeira e socialmente, quem atuar como protagonista ou parceiro no engajamento e na defesa de valores éticos;

- atuar de maneira a estimular a educação permanente em temas bioéticos.

\section{Abordagem para cada meio de comunicação}

Para Duarte ${ }^{25}$, o ato de comunicar deixou de indicar a disseminação ou o transporte de informação, equívoco clássico da área, e assumiu seu significado original de compartilhar, pôr em comum, dialogar, ouvir - uma espécie de bem direito coletivo universal: Estamos em tempos de novas arenas comunicativas, de interações complexas e perigosamente fluidas e fugidias com os diferentes públicos. O compartilhamento das informações vem ganhando, aos poucos, formas e meios mais democráticos para a promoção do diálogo. A internet é o símbolo maior da sociedade na era da telecomunicação, informática e comunicação - tele-info-comunicação.

Os celulares não cumprem apenas a função de colocar duas ou mais pessoas em contato. Hoje, esse aparelho é um conversor de mídia e de informações. Os usuários os utilizam para navegar na internet, participar de maneira móvel das redes sociais, tirar fotos, documentar fatos e reproduzir informações. As plataformas wikis, com conteúdo feito a partir de participação coletiva, e o surgimento das redes e espaços virtuais sociais como blogs, Facebook, Orkut, Twitter, MySpace, Linked in, Digg, You Tube, Second 
Life e Flickr colocam o desafio de superar a prática da comunicação de simplesmente informar numa direção única. O que se observa e estimula nesses canais é a interatividade - em todo o mundo foram criadas comunidades virtuais segmentadas que trocam e debatem informações sobre os assuntos mais diversos.

Todas essas características desse mundo plural e globalizado estão sendo levadas em consideração na proposição deste plano de comunicação, sem deixar de lado os meios mais tradicionais - já que o objetivo seria alcançar o maior público possível, com o menor custo possível. Rabelo sintetiza a importância e o alcance das mídias sociais: Abrangendo inúmeras áreas de enfoque ou conteúdo, as mídias sociais permitem, além da comunicação $e$ publicação propriamente ditas, uma efetividade nunca antes vista em termos de transmissão de conceitos, iniciativas de mobilização, estruturação de redes colaborativas e diversas formas de ação social coordenada, dando aos seus usuários um inaudito poder de barganha frente aos tradicionais detentores do poder nos campos sociais da comunicação e da política ${ }^{26}$.

As diversas estratégias de comunicação para cada um dos meios a serem utilizados precisariam ser trabalhadas. Mais uma vez, faz-se preciso reforçar que devem ser contextualizadas e adaptadas dependendo do lugar onde sejam criadas e das características socioculturais da população a que se dirigem. De maneira geral, seguem algumas ações.

\section{Internet, mídias sociais e mídias digitais}

Entre outros aspectos, o plano incluiria a criação de um portal no site da Unesco com:

- conteúdos explicativos e informativos, em diversas línguas, para consulta de públicos segmentados e de qualquer pessoa;

- elaboração de kits com conteúdos textuais e gráficos, bem como produtos com informações oficiais sobre bioética e DUBDH;

- criação, nas redes sociais, de perfis oficiais da Declaração ou sobre bioética;

- produção de filmes promocionais curtos que abordem situações e conteúdos relacionados a valores e ao contexto da Declaração, com divulgação nos canais das redes sociais e no You Tube;

- realização de chats periódicos com especialistas em bioética em cada um dos países;
- estímulo à criação de blogs na área de bioética ou relacionada a temas bioéticos em que especialistas possam dividir seu conhecimento;

- realização de parceria com o Google Maps para a criação de um mapa especial para marcar os endereços mundiais onde a bioética é estudada e onde as pessoas podem achar cursos na área;

- mobilização das redes governamentais (secretarias estaduais e municipais de Educação e Saúde, por exemplo) e não governamentais que trabaIhem com os temas bioéticos.

Outras mídias: jornais, televisões, rádios e revistas

Como visto, a internet é um meio impactante para levar as premissas da Declaração Universal sobre Bioética e Direitos Humanos da Unesco mundo afora. Mas os meios de comunicação são complementares. Por questões culturais e sociais, há pessoas que não possuem acesso à comunicação multimídia e não podem ficar alijadas desse processo interativo da comunicação - elas se informam por diversos outros veículos.

Em grandes esforços de comunicação, como a divulgação de uma campanha de vacinação num país continental como o Brasil, todos os meios são conjugados para que a mensagem seja captada e compreendida e o objetivo final seja cumprido. Tal estratégia de comunicação garante uma cobertura vacinal expressiva e, consequentemente, aumenta as chances de uma política pública cumprir seu papel.

O plano de comunicação para a DUBDH ora proposto prevê a divulgação de ideias, exemplos e casos práticos, em formato de pauta para reportagens em jornais, televisões, rádios e revistas. Os Estados nacionais e a Unesco, em parceria com a sociedade civil, setor empresarial e as entidades de classe, teriam o papel de envolver as empresas de comunicação públicas e privadas nesta corrente em prol da cidadania e de um mundo mais justo socialmente e sustentável.

As empresas de comunicação precisariam ser sensibilizadas quanto a esse esforço de comunicação, desde o pequeno ao grande empresário. Os grupos hegemônicos de comunicação deveriam ser chamados para este diálogo e para assumirem um comprometimento moral com os assuntos. Ao mesmo tempo, os principais influenciadores da mídia alternativa também deveriam participar deste diálogo 
com o governo e a Unesco. Os pequenos veículos poderiam reproduzir mensagens e influenciar populações excluídas e sem acesso aos principais veículos de comunicação.

Para alcançar públicos em lugares remotos, seria possível que, por meio de parceria entre o setor público e privado, fossem desenvolvidos programas presenciais de repasse de conteúdo ou a divulgação das mensagens com conteúdos bioéticos por rádios comunitárias. Alguns programas de rádio poderiam ser criados e distribuídos gratuitamente para que os habitantes da localidade entrem em contato com premissas estruturais e lutem por uma vida melhor.

\section{Comunicação publicitária e eventos}

A comunicação é múltipla e passa suas mensagens de diversas maneiras. Cada vez mais, a publicidade e a promoção de eventos agregam e diversificam as formas de transmissão de conteúdos. Muitas vezes, determinados conceitos e produtos têm maior aceitação do público quando essas ferramentas são acionadas. A seguir, algumas ações sugeridas no plano:

- criar o Dia Mundial de Bioética e Direitos Humanos, que seria comemorado em 19 de outubro, data da aprovação do documento. A criação dessa data teria importante caráter político para rememorar os compromissos que cada país terá assumido para que as ideias da Declaração sejam disseminadas e por tornar os vulneráveis mais incluídos socialmente;

- produzir campanha publicitária anual para ser veiculada em diversos meios de comunicação e nas redes sociais;

- nomear, em cada país, um embaixador da DUBDH sobre bioética, com uma agenda propositiva;

- criar uma pulseira, ou outro objeto, para simbolizar a adesão do cidadão comum aos objetivos da bioética e, consequentemente, dar visibilidade ao processo. O produto seria vendido a preço simbólico, e o dinheiro posteriormente revertido em projetos de divulgação dos valores da Declaração.

\section{Educação permanente}

Todas essas ações de comunicação descritas não sobrevivem sem que haja educação permanente por trás de um grande projeto e plano de divulgação. Sabe-se que a educação é o pilar transformador da realidade. Todas as esferas que têm influência no processo educativo, quer família, comunidade, organizações não governamentais e até o governo, devem se envolver no processo para alcançar o fim almejado: a educação de um povo para a cidadania consciente.

Embora não seja ação direta de comunicação, o processo educativo tem papel essencial na formação do cidadão, na transformação da pessoa em um ser político com capacidade de debater, de posicionar-se e de intervir no meio onde vive. A bioética de intervenção acredita nesse poder mobilizador e revolucionário da educação, que pode ocorrer das mais diversas formas e em níveis sociais distintos.

Nesse sentido, o plano de comunicação aqui proposto para divulgar e popularizar os valores da DUBDH defende que o assunto e os conceitos bioéticos - teóricos e aplicados - estejam presentes no nível mais básico do ensino formal até nos mais avançados. Não é possível avançar no grau de consciência e de interferência do ser humano, e consequentemente na autonomia e na liberdade, sem passar por processo educativo amplo, que promova a reflexão e a compreensão do mundo ao redor.

\section{Considerações finais}

Definitivamente, a Declaração Universal sobre Bioética e Direitos Humanos está no centro de muitos debates mundiais da atualidade. Porém, o que se percebe é que o desconhecimento generalizado sobre seu conteúdo - por parte da sociedade civil, dos profissionais de comunicação, dos gestores públicos e políticos e dos pesquisadores em geral mantém grande parte da população mundial excluída da participação e da tomada de decisões políticas importantes.

Por isso, mais do que necessário, é fundamental que se tenham diretrizes de comunicação nas áreas pública e privada que construam um diálogo mais produtivo entre as forças de poder. O presente trabalho apresenta uma proposta de um plano de comunicação com possibilidade de divulgar e promover a DUBDH. Isto pode ser feito por meio das mais diversas ferramentas de comunicação e educação que possibilitem tornar a bioética mais conhecida e visível pela população em geral. Esta política na área não deve só permitir a troca e o debate de informações, mas também ajudar na capacitação de atores participantes, para que possam construir e intervir no rumo das políticas públicas para um país ou para a humanidade. 
O resultado de uma mobilização do tipo pretendido com a presente proposta, decorrente de ações e estratégias de comunicação, pode ser revelador. A união de esforços pode ampliar o conhecimento e o entendimento das pessoas em diversas questões morais importantes, como acesso das populações a serviços de saúde de qualidade. Outra consequência da atuação direcionada em comunicação é que, a partir da capacitação de determinados personagens, eles possam atuar de maneira mais qualificada no controle social de questões importantes. Como consequência desse processo mobilizador, mudanças podem emergir e transformar realidades de maneira geral ou mais específicas, com a inclusão social de populações mais vulneráveis.

Politizar a comunicação, como a bioética de intervenção sugere para outros temas de conflitos e de situações persistentes e emergentes, é o caminho aqui proposto para que importantes decisões possam ser tomadas em prol da coletividade. Se- gundo Porto e Garrafa, a bioética de intervenção preconiza como moralmente justificável na esfera pública a priorização de políticas que privilegiem o maior número de pessoas, pelo maior tempo possível, e que resultem no bem comum ${ }^{27}$.

Nesse sentido, o plano também pode ser encarado como ato político e inclusivo. A bioética é uma ação transformadora do real ${ }^{28}$ e a comunicação é capaz de promover e provocar mudanças práticas na geopolítica mundial, com grande potencial de empoderar populações mais vulneráveis ${ }^{29}$ e, consequentemente, ajudá-las no processo de libertação, diminuindo a dependência e aumentando o poder de voz e veto ${ }^{30}$. Por fim, como resultado de um processo complexo, a comunicação pode servir de ferramenta para ajudar na emancipação dos sujeitos sociais mais carentes ${ }^{12}$, com amplas chances dos mesmos aumentarem sua participação política e vivenciarem, na prática, a tão almejada cidadania.

Trabalho produzido no âmbito da Cátedra Unesco e Programa de Pós-Graduação em Bioética da Universidade de Brasília, como projeto de dissertação.

\section{Referências}

1. Sané P. Aplicación de la declaración sobre bioética y derechos humanos. Revista Brasileira de Bioética. 2006;2(4):437-42.

2. Saada A. La declaración universal sobre bioética y derechos humanos: ampliación democrática para una sociedad más justa. Revista Brasileira de Bioética. 2006;2(4):413-22.

3. Barbosa S. A participação brasileira na construção da declaração universal sobre bioética e direitos humanos da Unesco. Revista Brasileira de Bioética. 2006;2(4):423-42.

4. Organização das Nações Unidas para a Educação, a Ciência e a Cultura. Declaração universal sobre bioética e direitos humanos. [Internet]. Paris: Unesco; 2005 (acesso 6 nov. 2010). Disponível: www.bioetica.catedraunesco.unb.br

5. Garrafa V, Lorenzo C. Helsinque 2008: redução de proteção e maximização de interesses privados. Rev Assoc Méd Bras. 2009;55(4):514-8.

6. Wisner B. Disaster vulnerability: scale, power e daily life. Geojournal. 1993;30(32):127-40.

7. Programa das Nações Unidas para o Desenvolvimento. Os objetivos de desenvolvimento do milênio: 8 objetivos para 2015. [Internet]. 2010 (acesso 6 jan. 2011). Disponível: http://www. pnud.org.br/odm/

8. Marques-de-Melo J. Comunicação social: teoria e pesquisa. Petrópolis: Vozes; 1970.

9. Garrafa V, Porto D. Intervention bioethics: a proposal for peripheral countries in a context of power and injustice. Bioethics. 2003;17:399-416.

10. Garrafa V, Porto D. Bioética, poder e injustiça: por uma ética de intervenção. In: Garrafa V, Pessini L, organizadores. Bioética: poder e injustiça. São Paulo: Loyola; 2003. p. 35-44.

11. Castoriades C. O mundo fragmentado: as encruzilhadas do labirinto 3. São Paulo: Paz e Terra; 1992.

12. Garrafa V. Inclusão social no contexto político da bioética. Revista Brasileira de Bioética. 2005;1(2):122-32.

13. Freire P. Extensão ou comunicação? São Paulo: Paz e Terra; 1971. p. 67-9.

14. Castells M. A era da informação: economia, sociedade e cultura. São Paulo: Paz e Terra; 1999. p. 411-39.

15. Kunsch MMK. Relações públicas e modernidade: novos paradigmas na comunicação organizacional. São Paulo: Summus; 1997.

16. Schramm FR. Bioética e comunicação em oncologia. Rev Bras Cancerol. 2001;47(1):25-32

17. Castells M. A era da intercomunicação. Le Monde Diplomatique Brasil. [Internet]. $1^{\circ}$ ago. 2006 (acesso 6 jan. 2011); Biblioteca virtual. Disponível: http://www.diplomatique.org.br/acervo. php?id=1915 
18. Tealdi JC. Para una declaración universal de bioética y derechos humanos: una visión de América Latina. Revista Brasileira de Bioética. 2005;1(1):7-17.

19. Gonçalves MAS. Teoria de ação comunicativa de Habermas: possibilidades de uma ação educativa de cunho interdisciplinar na escola. Educação e Sociedade. 1999;20(66):125-40.

20. Silva JG, Marinho Jr IB. Socialização da informação: aportes da teoria comunicativa. Ciência da Informação. 1996;25(3):466-72.

21. Miguel LF. Os meios de comunicação e a prática política. São Paulo. Lua Nova. [Internet]. 2002 (acesso jan. 2011);(55-56):155-84. Disponível: http://www.scielo.br/pdf/ln/n55-56/a07n5556. pdf

22. McLoughlin B. Um plano de comunicação eficaz. HSM Management. [Internet]. 2004 (acesso jan. 2011). Disponível: http://www.professoracintia.com.br/tecnicas_de_negociacao/um\%20 plano\%20de\%20comunica\%E7ao\%20eficaz.pdf

23. Wolf M. Teorie delle comunicazioni di massa. Milão: Bompiani; 1985.

24. Miguel LF. Representação política em 3-D: elementos para uma teoria ampliada da representação política. Revista Brasileira de Ciências Sociais. 2003;18(51):123-40.

25. Gramacho W, Mello R. Mapa da comunicação brasileira. Brasília: Instituto FSB Pesquisa; 2009. p. 46-7.

26. Rabelo L. As mídias sociais e a esfera pública: mudanças de paradigma na comunicação contemporânea. In: Anais do XII Congresso de Ciências da Comunicação na Região Centro-Oeste; 27-29 maio 2010; Goiânia. [Internet]. Goiânia: Intercom Centro-Oeste; 2010 (acesso jan. 2011). Disponível: http://www.intercom.org.br/papers/regionais/centrooeste2010/resumos/R21-03381.pdf

27. Porto D, Garrafa V. Bioética de intervenção: considerações sobre a economia de mercado. Rev. bioét. (Impr.). 2005;13(1):111-23.

28. Neves MCP, Osswald W. Bioética simples. Lisboa: Editora Verbo; 2007. p. 79-111.

29. Sen A. Desenvolvimento como liberdade. São Paulo: Companhia das Letras; 2000

30. Freire P. Pedagogia da autonomia. São Paulo: Paz e Terra; 2001.

\section{Participação dos autores}

Rodrigo Caetano participou da concepção, organização e execução da pesquisa, além da redação final do texto. Volnei Garrafa, como orientador, participou de todas as etapas da pesquisa.

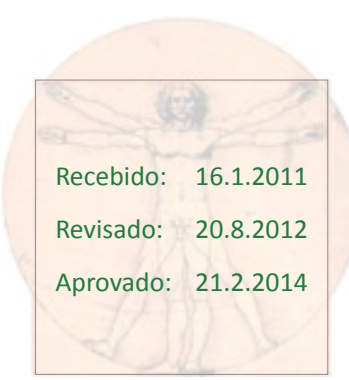

